\title{
Seed Reproduction technology of the Magnolia grandiflora from seeds
}

\author{
Ruziboy Bakhramov ${ }^{1 *}$, Xamza Yuldashev ${ }^{1}$, Feruza Tokhtaboeva $^{2}$, Ergashali Ro'zimatov ${ }^{2}$, Gulmira $_{\text {Ergasheva }}{ }^{2}$, Saodat \\ Mirzaeva $^{2}$ \\ ${ }^{1}$ Research Institute of Forestry, 111104 Tashkent, Uzbekistan \\ ${ }^{2}$ Andijan State University, 170100 Andijan, Uzbekistan
}

\begin{abstract}
This article highlights the results obtained on the basis of scientific research carried out in 20192020 on the technology of reproduction from the seeds of Magnolia grandiflora plant in the farmer's farm named "Saydullo Temirov" specialized in the cultivation of landscape trees and shrubs located in the Uighur village of Pakhtaobod District of Andijan region. As a result of the study, determination of seed stratification time, planting time and methods, as well as maintenance work were determined, and conclusions were made.
\end{abstract}

\section{Introduction}

The rapid development of urbanization in the world requires the development of intensive methods of landscaping, beautification and improving the microclimate. At this point, the species selected for landscaping are mainly important for their permanent greenery, as well as high landscape, promising reproductive potential and rapid growth. Accordingly, based on these indicators, the selection and introduction into production of individual groups of plants that are resistant to local conditions, highly scenic, economically valuable, has scientific and practical significance [14].

Particular attention is paid to research to identify high-scenic, promising, resistant to various external pests' plant species and the development of effective methods of rapid reproduction as a priority of landscaping in the world. In this regard, new varieties and forms of ornamental species have been created. The potential of trees and shrubs in modern landscaping has been assessed, new methods of vegetative propagation have been developed, and optimal methods of seed propagation have been improved. Magnolia Grandiflora, which is widely used in landscaping and beautification, is of particular importance for its uniqueness and high visibility, resistance to adverse environmental factors, the release of phytoncides that cause disease and fight infectious bacteria [5,6]. There are 46 species of this family in the United States, more than 10 species in the Botanical Garden of the United Kingdom, more than 15 species in the botanical gardens of Japan and China, and 9 species and 3 hybrid forms in Palm.

The Magnolia plant is a decorative and landscape plant, which attracted a lot of scientists and the interest of climatologists (intraductors). This plant lives 60-70 years. Some representatives do not shed leaves, while others shed leaves. The leaves are large and shiny, the flowers are also large and rich in essential oil, and bloom from February to October. There was a need to create industrial-scale developments of magnolia seeds and vegetative propagation.

Agranom Farazov first brought 4 Magnolia grandiflora plants from Georgia to Uzbekistan in 1964 and planted them in Namangan city administration field. Later, in 1972-1975 Murzova [7] worked on acclimatization of Sulanja, Cobus, Tripetala species of magnolia and a large-flowered magnolia plant in the Tashkent Botanical Garden under the Institute of Botany of the Academy of Sciences of the Republic of Uzbekistan. Today, these trees are used as mother trees.

Based on the above data, it was determined that the volume of cultivation of Magnolia grandiflora in the Republic, the level of formation of seed reserves and agro-technologies for their cultivation have not been developed. For this reason, it was considered expedient to conduct scientific research to determine the biological properties of this plant and to develop effective methods to increase its productivity.

Homeland magnolia is South America (Florida), an evergreen tree up to 30 meters tall. The leaves are simple, large, glossy, with a thick bark, the edges are entire, they are located in short bands. The flowers are large $(15-17 \mathrm{~cm})$ solitary, the place is long, conical. The leaves of the cauliflower consist of 6-12 white fragrant leaves, arranged in three circles. The dusters are many and wide-threaded. The seeds also have many fruit petals, which are arranged in a

*Corresponding author: ruziboybahramov68@gmail.com 
spiral instead of a flower. Each fruit leaf forms a separate seed. The edges of the seed leaves turn towards its middle root, forming a single-celled, two-seeded nodule. Without the seed column, the top of it is occupied by the beak, which traps the dust. When the flowers wither, the leaves and pollen of the cauliflower fall off, leaving only traces. The flower bed grows, and the seeds produce hard gray leafy fruits. Leaf ball fruits open with abdominal seams, forming "domes" of 5-6 cm and longer. Mature seeds have a soft reddish seed coat that hangs using long strings.

The fruits of the magnolia plant are elongated, ovoid, red, 8.0-12.0 cm long. The seeds are 9-11 mm long, 7-8 mm wide and 4.5-5.0 $\mathrm{mm}$ thick. It has an elongated heart-shaped appearance, a little shiny, and the skin is red. The weight of one seed is 3.75 grams with a peel, up to 0.073 grams without peel.

In one fruit Dome of the Magnolia under study, there are seeds up to 30-155 soles, while the actual seed fertility is 1155 grains in one dome.

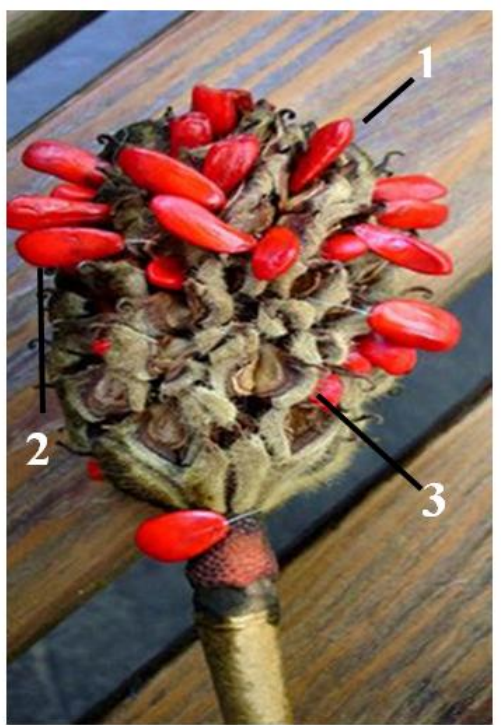

Fig. 1. A general view of the ripened seeds of Magnolia grandiflora: 1-red shell, covering the seeds, 2-the thread that hangs the ripened seed on its dome, 3 -fruit Dome

The study of the properties of Magnolia seeds in specific natural-climatic conditions of reproduction is not only theoretical, but also practical in its introduction and solution of breeding issues $[8,9,10]$.

The fruit of Magnolia is a apocarp (occurring in a flower from a separate motherhood) fruit, consisting of polyspermia (fertilization of the secondary nucleus with sperm from the sperm cell and the secondary nucleus to ten) fruits (Figure 1). The domium of the formed seeds is formed by the method of opening - as a result of a steep rupture of the fruit Dome. The ripened seeds are hung open to the fruit dome (Fig. 1). The seeds are covered with a sarkotesta (the outer part of the skin of the seed), which has a bright color from light pink to dark red [11].

\section{Materials and Methods}

For the experience of breeding the Magnolia grandiflora plant from seeds, the seeds collected in November 2019-th year were used. Work on determining the fertility of seeds in laboratory conditions began in the second decade of December 2020-th year. In laboratory conditions, Cup petri, filter paper, distilled water and $90 \%$ ethyl alcohol were used to determine the fertility of the Magnolia grandiflora plant. Observations were conducted on four cups of petri dish.

Before placing the seeds in a cup petri dish, the petri dish was thoroughly wiped with $90 \%$ ethyl alcohol. The purpose of this work is to completely disinfect the cup petri and to preserve the quality of the seeds for a long time. The seeds were kept in a $0.01 \%$ solution of the drug "Maxim" for a while to protect against various fungal diseases. Considering the size of each, the seeds were placed in 25 cups in a petri dish and stored in a thermostat at $+25{ }^{0} \mathrm{C}$ and the germination rate was observed.

Phenological monitoring of the growth and development of seeds of Magnolia grandiflora in laboratory conditions began on 1 January 2020. Since the seeds placed for the purpose of checking the germination did not pass the stratification period, the state of germination was not observed in our seeds placed in cup petri. However, the fertility of the seeds that passed the stratification process was determined in the laboratory of Andijan branch of the Scientific 
Research Institute of Forestry. On March 25, 2020, the fertility of seeds that have passed the full stratification period was studied in laboratory conditions.

\section{Results and Discussions}

During the experiments, the fertility of seeds was determined from $25 \%$ to $50 \%$. As can be seen from experiments, the fertility of seeds in laboratory conditions is much lower. The results can be seen in the tables and figures below (Table 1 and Fig. 2).

Table 1. Magnolia grandiflora seeds are an indicator of fertility in conditions of laboratory (Cup petri)

\begin{tabular}{|c|c|c|c|c|c|c|c|c|}
\hline \multirow[t]{2}{*}{ № } & \multirow[t]{2}{*}{ Weight of 25 seeds, gramm } & \multicolumn{7}{|c|}{ Fertility of seeds, pcs } \\
\hline & & $\begin{array}{l}\overrightarrow{\widehat{े}} \\
\text { ஸे } \\
\dot{0} \\
\dot{0}\end{array}$ & 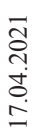 & 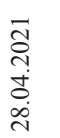 & 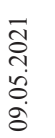 & 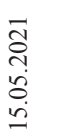 & 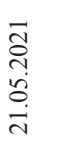 & 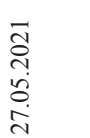 \\
\hline 1 & 1.91 & 4 & 7 & 9 & 9 & 11 & 11 & 11 \\
\hline 2 & 1.85 & 3 & 5 & 6 & 6 & 7 & 7 & 7 \\
\hline 3 & 1.78 & 1 & 1 & 1 & 2 & 3 & 6 & 6 \\
\hline 4 & 1.78 & 1 & 1 & 1 & 3 & 4 & 6 & 7 \\
\hline
\end{tabular}

As can be seen from Table 1 Above, the fertility of the seeds was observed in the seeds in the cup of petri dish, in which the total weight was more. The reason is that it is known from experiments that well-ripened, full-bodied seeds have a good state of germination.

Increasing the effectiveness of Magnolia seed propagation depends on the correct choice of the place and time of planting, the use of quality seeds. Since the seeds of Magnolia are wrapped in a red shell, it requires a longer stratification than other seeds. This is of great importance not only for the germination of the seed, but also for the development of its embryo $[12,13]$.

A number of scientists recommend stratification of magnolia seeds at a temperature of $5-8{ }^{\circ} \mathrm{C}$ for a period of one to six months. As a substrate, it is recommended to use a mixture of sphagnum moss, moss, or sand [7, 14-20].
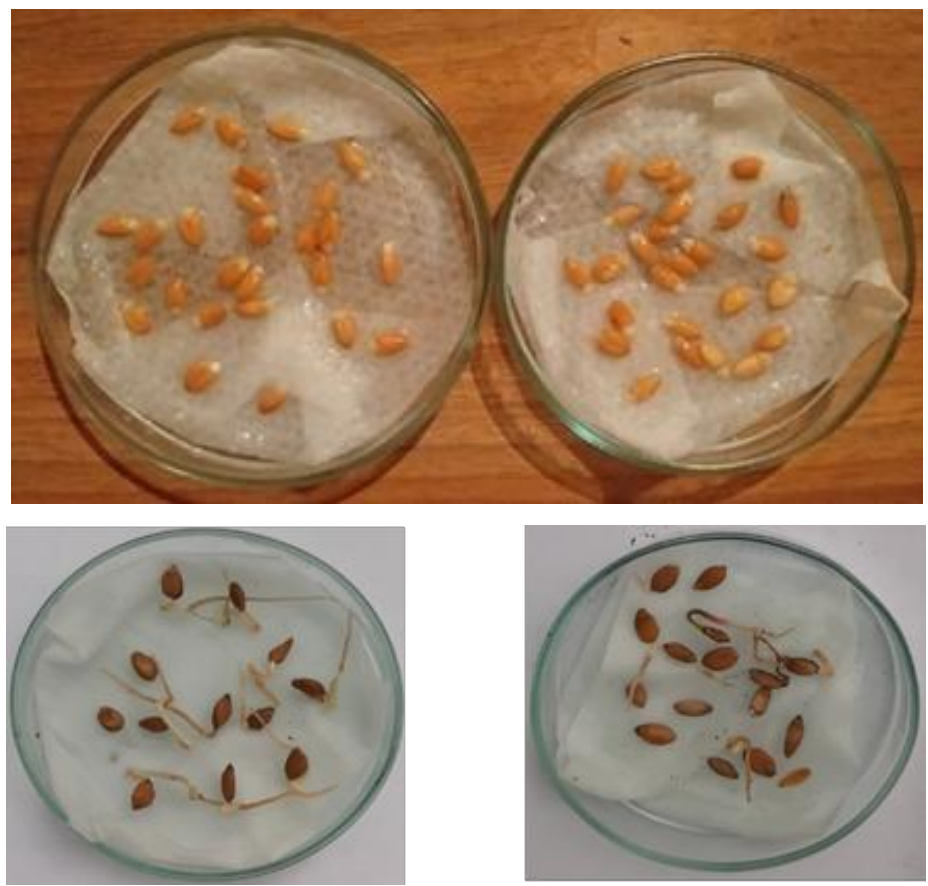

Fig. 2. The process of germination of seeds that have passed the stratification stage 
For planting magnolia seeds in field conditions, the ripened seeds were harvested in October-November 2019 and were divided into 3 groups (Large, Medium, Small) depending on their large size. The weight of the seed, which was made from 100 grains with red peel (sarkotesta) and without Peel, was determined using analytical scales and prepared for the experiment. In order to determine the germination of seeds in field conditions, on December 5, 2020, year (without stratification) 500 units of seeds were planted in two variants: 250 units of seeds with a red coat and 250 units of seeds without a red coat.

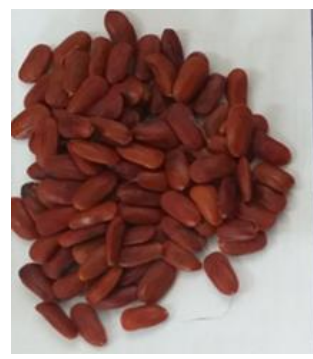

Large (100pcs/267g)

Fig. 3. Magnolia grandiflora seeds

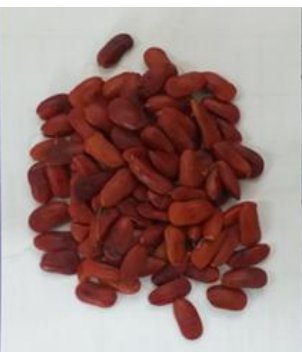

Medium (100pcs/215g)

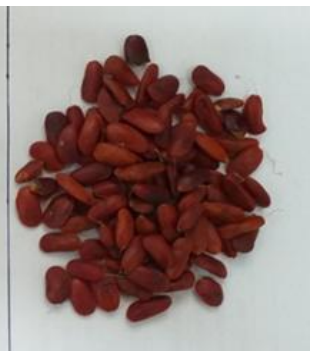

Small (100pcs/17.5g)

Magnolia seeds, planted with a red peel and without a peel, spent the winter dormancy in an open place. In order to save the seed from external unfavorable factors on the planted area, the remains of soil and leaves were discarded as mulch. During the observation, no irrigation work and technical measures were carried out on the seeds planted in the open field. The process of development in 250 units of red-ripened seeds, planted for experiment, began with the first decade of May 2020 year and continued until the last decade. However, in our seeds planted without red peel, the process of development was much slower, and there was a significant decrease in fertility. This is because they are planted without red peel. This was due to the drying of the seeds and the preservation of them from the various effects of external environmental factors. Thus, out of a total of 500 seeds, 236 seed germination was maintained. These figures accounted for 175 seeds, or $60.1 \%$ of seeds sown with red bark, and 61 seeds, or $22 \%$ of seeds sown without red bark.

Table 2. An indicator of germination of Magnolia grandiflora seeds in laboratory (soil) conditions

\begin{tabular}{|c|c|c|c|c|c|c|c|}
\hline \multirow[t]{2}{*}{ № } & \multirow{2}{*}{ Sowing of 250 seeds } & \multicolumn{6}{|c|}{ Fertility of seeds, pcs } \\
\hline & & 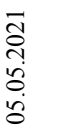 & 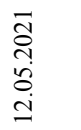 & 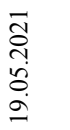 & 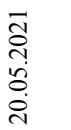 & 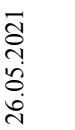 & 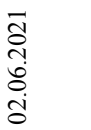 \\
\hline 1 & With red bark & 24 & 47 & 73 & 139 & 151 & 175 \\
\hline 2 & Without red bark & 8 & 10 & 14 & 29 & 45 & 61 \\
\hline
\end{tabular}

Low fertility of seeds of the Magnolia plant is because in one fruit dome up to 30-50 soles of seeds are formed, which is due to the abundance of the total number of seeds. Even with an average yield coefficient, sufficient whole seeds are formed to ensure the regeneration of the seeds [21].

Scientists engaged in the reproduction of the Magnolia grandiflora plant in many countries around the World explain the reasons for the low prevalence of the germination of the seed of the plant mainly as follows: Magnoliaphta branch, Magnoliales (Magnoliales) tribe. The process of seed formation in belonging trees and shrubs occurs mainly in the presence of domes [22]. For this reason, the fertile part of the fruit leaf of the seed plants developing polyspermia triples to the degeneration of the deficiency of nutrients in the process of the formation of fruit nodes (carpels) along with the ovary. And these processes are considered one of the most important processes in the life of plants [23-26].

Magnolia seeds have a red shell (Figure 1). This reduces their drying and germination. It is therefore recommended to remove the red fleshy part when sowing seeds as because it delays the germination of seeds and prevents them from developing well [17, 27-30]. In addition, magnolia seeds sown with red skin are more susceptible to various diseases and the attraction of microorganisms.

Proceeding from the above recommendations, we saved 2000 pieces (560 gr) of Magnolia grandiflora seeds in a fourmonth period (from 15.11.2019 to March 2020 year in the second decade) in the refrigerator at a temperature of $+50 \mathrm{C}$ in the case of burial of seeds in a clean river sand with a red peel for the purpose of stratification.

Contrary to the experience of some scientists in the stratification of seeds, the seeds were kept in a low-temperature outdoor environment for a week without removing moisture from the sand, and stratification was carried out by repeated storage in a refrigerator at $+50 \mathrm{C}$. First, the seeds were separated from the sand and red shell. It was then 
washed using household soap as an alkali. The prepared seeds were sown in a specially allotted area prepared in four different variants. At the same time, a total of 4 square meters of land was dug at a depth of $25 \mathrm{~cm}$ at four different points in the experimental area, considering the fact that the experimental seeds have a strong root system. $1 \mathrm{sq} \mathrm{m}$ area was retained as a control variant. The remaining $3 \mathrm{sq} \mathrm{m}$ area was filled with $1 \mathrm{sq} \mathrm{m}$ of pure river sand, $1 \mathrm{sq} \mathrm{m}$ of coconut peat and the remaining $1 \mathrm{sq} \mathrm{m}$ of sand, organic fertilizer (manure) and soil mixed substrate in a 1:2: 1 ratio. 500 seeds for each variant were sown on March 25, 2020 (Table 3). The options in the first two areas were not given special attention as they had shown their results in previous experiments. However, the upper part of the experimental area filled with coconut peat was covered with cellophane film in order to maintain a moderate level of moisture. The area filled with organic fertilizer was watered three times more than the remaining areas (options). The reason for this is to reduce the negative impact of organic fertilizer on the root because of heating.

Table 3. Determination of germination rate of Magnolia grandiflora seeds in soil conditions in the open field

\begin{tabular}{|c|c|c|c|c|c|c|c|c|}
\hline № & Experiments & $\begin{array}{l}\overrightarrow{\widetilde{a}} \\
\text { ते } \\
\dot{0} \\
\dot{d}\end{array}$ & 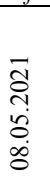 & $\begin{array}{l}\vec{̃} \\
\text { ก̦ } \\
\vdots \\
0 \\
0\end{array}$ & 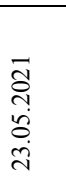 & 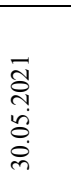 & 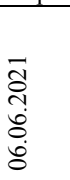 & $\begin{array}{c}\text { Number of } \\
\text { seedlings } \\
\text { preserved at the } \\
\text { end of the year }\end{array}$ \\
\hline 1 & Clean soil (control version) & & 18 & 94 & 204 & 300 & 383 & 340 \\
\hline 2 & River sand & & 21 & 89 & 200 & 294 & 332 & 327 \\
\hline 3 & Coconut peat & 5 & 29 & 99 & 223 & 301 & 370 & 363 \\
\hline 4 & $\begin{array}{l}\text { sand, organic fertilizer (manure) and } \\
\text { soil, (1:2: } 1 \text { ratio respectively) }\end{array}$ & & 17 & 91 & 210 & 289 & 333 & 318 \\
\hline
\end{tabular}

In our experiment, when observing the germination of seeds, the third variant of the germination process began to develop ten days earlier than the other variants because the seeds were covered with cellophane film.

A total of 2,000 (560 g) seeds sown from 500 seeds in each of the four varieties were calculated as the percentage of seed germination in the varietal section. In the control variant, 383 seedlings, or $68.1 \%$ of seed germination, were preserved. By the end of the growing season, the number of surviving seedlings was 340 , or $64 \%$. As for the control variant, the difference between the germination of seeds sown in coconut peat and the number of preserved seedlings was as follows: 370 seeds $(66.1 \%)$ germinated. By the end of the growing season, 363 seedlings (66\%) had survived. This is because coconut peat is rich in a soft nutrient medium and has a low density relative to the soil. As a result, the roots are well developed and the number of preserved seedlings are slightly higher.

\section{Conclusions}

Based on research on the technology of propagation of Magnolia grandiflora from seed, recommendations for seed storage and sowing have been developed:

1. Freshly harvested seeds should be stored at $+5{ }^{\circ} \mathrm{C}$ and $-18{ }^{\circ} \mathrm{C}$ in moist and clean river sand and substrate (moss, peat, sand, etc.).

2. It should be ensured that the seeds stay for 4 months or more during the stratification period.

3. Before sowing the stratified seeds, it is necessary to separate the red skin and carry out thorough processing in case of use of household soap as an alkali.

\section{References}

1. N. Toshpulatov, O. Tursunov, D. Kodirov, G. Kholmuratova, Environmentally friendly technology for the destruction of tobacco mosaic viruses (TMV) from selected species of plants, IOP Conf. Ser.: Earth Environ. Sci. 614, 012133 (2020)

2. J.W. Dobrowolski, O. Tursunov, O. Pirimov, O.J. Nazarova, Laser Biotechnology for Nutritional Health, Sustainable Environment and Development IOP Conf. Ser.: Earth Environ. Sci. 614, 012108 (2020)

3. H.A. Shouket, I. Ameen, O. Tursunov, K. Kholikova, O. Pirimov, N. Kurbonov, I. Ibragimov, B. Mukimov Study on industrial applications of papain: A succinct review IOP Conf. Ser.: Earth Environ. Sci. 614, 012171 (2020)

4. J.W. Dobrowolski, D. Bedla, T. Czech, F. Gambus, K. Gorecka, W. Kiszcak, T. Kuzniar, R. Mazur, A. Nowak, M. Sliwka, O. Tursunov, A. Wagner, J. Wieczorek, M. Swiatek, Integrated Innovative Biotechnology for Optimization of Environmental Bioprocesses and a Green Economy Optimization and Applicability of Bioprocesses eds H. Purohit, V. Kalia, A. Vaidya, A. Khardenavis (Singapore: Springer) chapter 3 pp 27-71 (2017)

5. A.M. Clark, A.S. El-Feraly, W.Sh. Li, Antimicrobial Activity of Phenolic Constituents of Magnolia Grandiflora L., J. Pharmaceutical Science, 70, 951-952 (1981) 
6. L.F. Ding, J. Su, Zh.H. Pan, Zh.J. Zhang, X.N. Li, L.D. Song, X.De. Wu, Q.Sh. Zhao, Cytotoxic sesquiterpenoids from the leaves of Magnolia grandiflora, Phytochemistry, 155, 182-190 (2018)

7. R.M. Murzova, Development of hard introduced deciduous species of the genus (Magnolia L.), Information Message, Moscow (1974).

8. I.V. Vainaigiy Вайнагиу, Method of studying the seed productivity of plants, Botanical Journal 59(6), 826-831 (1974)

9. P.E. Levina, The value of seed introduction, Biological bases of seed science and seed production of introduced species, Science, Novosibirsk (1974)

10. V.I. Nekrasov, Fundamentals of seed science of woody plants during introduction, Science, Moscow (1973).

11. Sh. Tojiboev, N. Ulukov, N. Rakhimova, Dictionary of Botanical Terms, "Namangan" Publishing House, Namangan (2014)

12. M.G. Nikolaeva, Physiology of deep dormancy of seeds, Science, Leningrad (1967).

13. M.G. Nikolaeva, Features of seed germination of plants from subclasses of Magnoliidae, Ranunculidae, Caryophyllidae and Hamamelididae, Botanical Journal 73(4), 508-521 (1988)

14. S.G. Ginkul, Magnolias in the Soviet subtropics, Ad-Jarii, Batumi, (1939).

15. A.B. Matinyan, Magnoliaceae in the Batumi Botanical Garden, GBS Bulletin 24, 3-11 (1956)

16. N.F. Minchenko, Seasonal development of obovate magnolia in Kiev, VII Congress of the Ukrainian Botanical Society, Kyiv (1982)

17. N.F. Minchenko, T.P. Korshuk, Magnolias in Ukraine, Science "Dumka”, Kyiv (1987).

18. K.P. Slipushenko, To the question of seed reproduction of magnolias, Journal of CRBS AS URSR 3, 28-33 (1961)

19. E.P. Slipushenko, Experience in the introduction of magnolias in the Lviv region, The experience of studying introduced plants in the southwestern zone of the USSR, Shtiintsa, Chisinau (1971)

20. C.Y. Han, G. Weibnum, C.L. Long, Seed dormancy and germination of Michelia yunnanensis (Magnoliaceae), Horticultural Science. 124, 83-87 (2010)

21. L.Ya. Fedorova, Reproductive biology and reproductive ecology of representatives of the genera of Cerasus, Microcerasus and Amygdalus (Rosaceae), Doctor of Biological Sciences Dissertation, Perm (2012)

22. A.L. Takhtadjan, Magnoliophyte system, Science, Leningrad, (1987).

23. G.M. Anisimova, Heterospermia. Embryology of flowering plants. Terminology and Concepts. Reproduction systems, Peace and Family 3, 279-286 (2000)

24. I.N. Beideman, Methods for studying the phenology of plants and plant communities. Science, Novosibirsk (1974)

25. I.I. Shamrov, Transport of metabolites and possible causes of the formation of aberrant ovules, Botanical Journal 90(11), 1664-1667 (2005)

26. O. Erdelska, Successive tissue degeneration in unfertilized ovules of Daphne arbuscula, Acta Biologica Cracoviensia ser. Botanica. 41, 163-167 (1999)

27. T.P. Korshuk, P.M. Palagecha, Magnolias (Magnolia L.), VPC Kyiv University, Kyiv (2007)

28. M.A. Afanasiev, Physiological study of dormancy seed of Magnolia acuminata. N.Y. (Cornell), Arg. Expt. Stan. Mem. 208, 37 (1937)

29. J. Corral-Aguirre, L.R. Sanchez-Velesquez, Seed ecology and germination treat-ments in Magnolia dealbata: An endangered species, Flora 201(3), 227-232 (2006)

30. C. Jacobo-Pereira, R. Romo-Campos, J. Flores, Seed germination of Magnolia pugana (Magnoliaceae), an endemic and endangered species from Western Mexico, Botanico Sciences 94(3), 1-10 (2016) 